\title{
THE MANAGEMENT OF WAR WOUNDS INVOLVING BONE
}

\author{
D. I. ROWLEY \\ From Dundee Royal Infirmary, Scotland
}

O ver 200 high-velocity missile injuries treated in a low-technology environment were audited under the aegis of the International Committee of the Red Cross Hospitals in Afghanistan and Northern Kenya.

Femoral fractures were treated either by traction or external fixation using a uniaxial frame. The results showed that patients treated by external fixation remained in hospital longer than those treated on traction. The positional outcome was identical in both groups. In tibial fractures the external fixator was only of extra benefit in those of the lower third when compared with simple plaster slabs unless more complex procedures such as flaps or vascular repair were to be performed. In complex humeral fractures, external fixation resulted in long stays in hospital and a large number of interventions when compared with simple treatment in a sling.

We conclude therefore that in an environment where facilities are limited and surgeons have only general experience very careful initial wound excision is the most important factor determining outcome. The application of complex holding techniques was generally inappropriate.

J Bone Joint Surg [Br] 1996;78-B:706-9.

Received 21 August 1995; Accepted after revision 25 March 1996

Modern high-energy weapons inflict severe damage to soft tissues and bone. The current view is that such injuries to the limbs should be treated near the scene of conflict, usually by external fixators, and the patients then evacuated from the battlefield for definitive treatment in fully-equipped hospitals. This works well for western armies, but has not been tested for large numbers of casualties.

In the former Yugoslavia local civilian centres of excel-

D. I. Rowley, BMed Biol, MD, FRCS, Professor of Orthopaedic and Trauma Surgery

University Department of Orthopaedic and Trauma Surgery, Caird Block, Royal Infirmary, Dundee DD1 9ND, UK.

(C)1996 British Editorial Society of Bone and Joint Surgery 0301-620X/96/51253\$2.00 lence were available (Korzinek, Smerdelj and Tripkovic 1991; Korzinek 1993), but in less developed countries where paramilitary and civil warfare may be rife any equivalent medical technology is usually lacking (Goonetilleke 1993) and the outcome is more dependent on organisation and evacuation than the quality of definitive surgery. Voluntary surgical support from 'non-governmental agencies' such as the Red Cross and Médecin Sans Frontiers is essential.

The International Committee of the Red Cross (ICRC) tries to provide surgeons who can deal with a spectrum of injuries (Coupland 1993), and has adopted a combination of external fixation, plaster stabilisation and traction for the primary management of missile injuries. A review of some of their records has provided the opportunity to study the outcome of bone and soft-tissue injuries to limbs in the Afghan and Sudanese conflicts of 1991 to 1993. There were limited facilities as regards location, equipment and specialist expertise. Almost 200 high-velocity gun-shot wounds treated largely by general surgeons with limited orthopaedic experience have been audited.

\section{PATIENTS AND METHODS}

Fractures of the femur, tibia and humerus excluding those involving joints were studied. The ICRC notes include a card on which a brief history and examination are recorded, with the wound scored by the ICRC system (Table I; Coupland 1990). This records the nature of the missile, any fragmentation, the entry and exit wounds, and damage to bone, soft tissues and the vital structures. It is known to have reasonable interobserver agreement. All injuries to the lower limbs which were studied had a complete ICRC wound score but the severity of injuries to the upper limbs was scored simply on the number of fragments and the recorded size of the wounds.

Radiographs of all the injuries were available, sequentially numbered and dated. Only patients with a complete radiographic record were included.

Early treatment was by debridement followed by external fixation, plaster slabs or traction. ICRC policy encourages careful excision of damaged soft tissues and removal of only non-viable bone, followed by delayed closure at five days using delayed primary suture or split-skin grafting. Skin flaps were rarely used. The AO external fixator was used in various uniaxial configurations, transfixing soft tissues only on one side of the bone. Traction for femoral fractures used a tibial bone pin with cords over single 


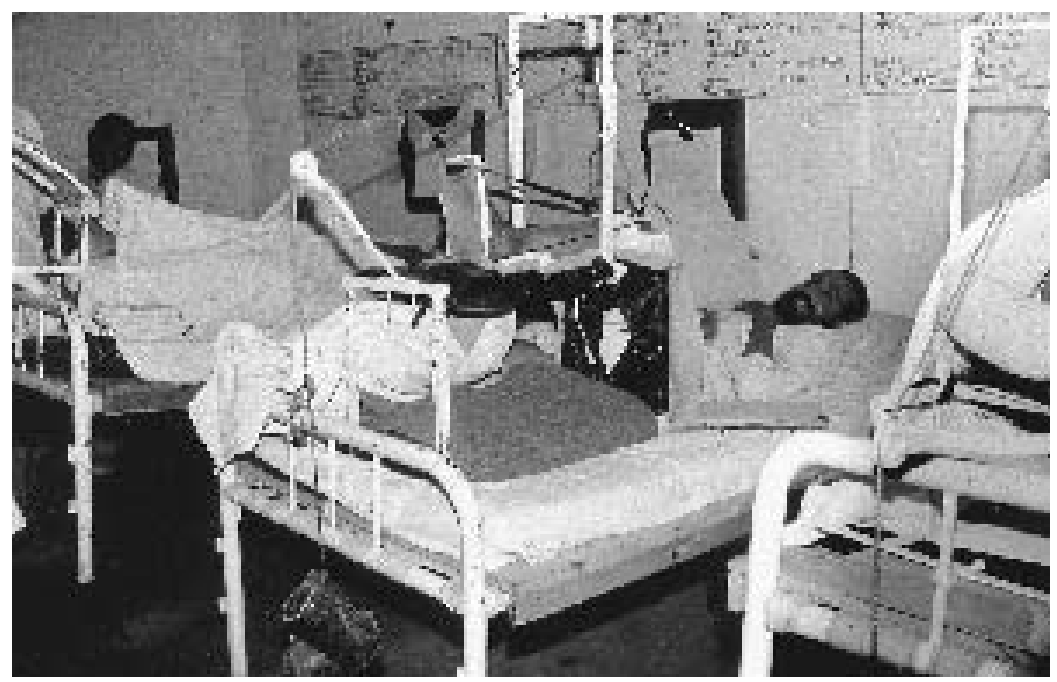

Fig. 1

The traction ward in Quetta, Baluchistan showing the practical use of ' $90-90$ ' traction frames manufactured at the hospital.

Table I. The ICRC wound classification system (Coupland 1990). The wounds are scored first and the score then used to grade the injuries into three groups
$\mathrm{X}$ Exit wound
$\mathrm{X}(\mathrm{cm})$ Maximum diameter of exit wound
E Entry wound
E $(\mathrm{cm})$ Maximum diameter of entry wound
C Size of cavity within limb
C1 Cavity will admit two fingers at surgery
Co Cavity will not admit two fingers at surgery

\section{F Fracture}
Fo No fracture
F1 Simple hole or insignificant comminution
F2 Clinically significant comminution
V Involvement of vital structure such as viscera or major vessel Vo No vital structure involved
V1 At least one vital structure involved
M Metallic bodies
Mo No bullet or fragments
M1 One metallic body
M2 Multiple metallic bodies

Grade $1 \mathrm{E}+\mathrm{X}$ is less than 10 with scores Co and Fo or F1 (lowenergy transfer)

Grade $2 \mathrm{E}+\mathrm{X}$ is less than 10 with scores $\mathrm{C} 1$ or F2 (high-energy transfer)

Grade $3 \mathrm{E}+\mathrm{X}$ is 10 or greater with scores $\mathrm{C} 1$ or F2 (massive wounds)

pulleys, and frames of various dimensions (Fig. 1). Plaster slabs padded with cotton wool were often used to maintain joints in functional position.

The hospitals. ICRC hospitals are not usually permanent, although the two described below have been functioning for many years because of continued military and political unrest. Local facilities and personnel are used as far as possible, with imported doctors, nurses and other paramedical staff. The usual team consists of a surgeon, an anaesthetist, a theatre nurse and a head nurse to take administrative charge. The basic surgical instruments are sterilised in autoclaves, but orthopaedic equipment is limited to simple bone pins, external fixators and plaster of
Paris. A few fine instruments are available for limited vascular and reconstructive surgery.

Lopiding Hospital in Kenya is adjacent to the border with Sudan and receives patients on average at least a week after injury. The operating room has three tables and there are usually two medical teams. The humeral fractures reviewed had been treated there.

Quetta Hospital in Baluchistan is almost 40 miles from the Afghan border. Patients usually arrive at a border firstaid station about four days after injury, and are then forwarded in a few hours. The femoral and tibial fractures had been treated at this hospital.

The patients who reach one of these two hospitals are only a small minority of the total number of casualties. Many die near the field of conflict through lack of immediate support and resuscitation, and the hospitals are dealing with relatively late survivors. Both military and civilian patients are seen, including children.

Wound and radiological assessment. For the three bones studied, the wounds were scored by ICRC methods or by the number of bone fragments. The complications were recorded for each injury and the outcome as the number of days in hospital. Radiographs were measured to assess shortening and angulation and compared with those taken after the second operation, when the wound had been closed. The latest radiograph was usually taken at the time of clinical healing and discharge from hospital.

\section{RESULTS}

Femoral fractures. Of the 86 open femoral fractures from Quetta Hospital most were Gustilo grade II or III. Nearly all the ICRC wound scores were in intermediate grade 2 indicating a high level of severity (Fig. 2). The initial debridement had usually been at five to seven days after injury.

Thirty-five fractures had been treated by external fixation and 51 by traction, with equal severity of injury in both 


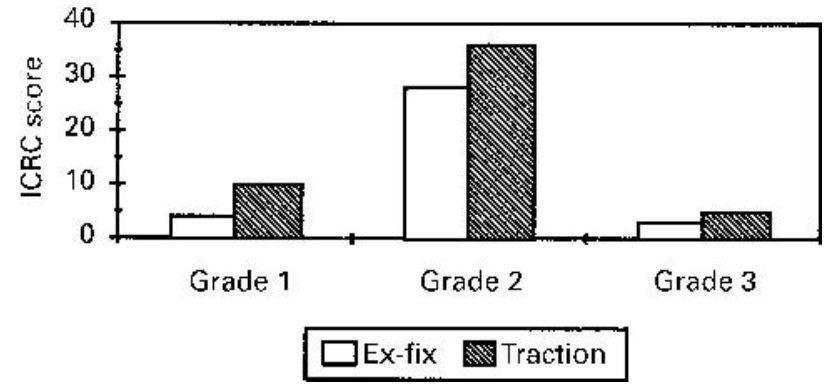

Fig. 2

The ICRC classification of the femoral fractures.

groups; the selection of method can be attributed to the preference of the surgeon. The use of external fixation did not reduce the average hospital stay ( 73 days, external fixation group; 66 days, traction group), although the length of this was partly due to the difficulty of discharging such patients to limited support facilities. Shortening was acceptable in both groups; external fixation was no more efficient in maintaining bone length than skilfully applied traction. In the externally fixed group it averaged $3 \mathrm{~cm}$ and was often associated with difficulties in siting pins in high femoral fractures (Fig. 3); it was only $1.2 \mathrm{~cm}$ in the group treated on traction.

Complications. The commonest complication was pin-track infection requiring resiting. Significant delay or nonunion was rare; all the femoral fractures united eventually. Some traction pins caused problems, but the notes show more anxiety and difficulty with pin siting in cases managed by external fixation. This led to a mean of 13 operative interventions in the externally fixed group compared with a mean of only eight adjustments or operations in the traction group.

On review, acceptable results had been achieved with traction and there were fewer problems. Limited later review of a few patients showed a surprisingly high incidence of stiff knees after external fixation of the femur.

Tibial fractures. Of 64 tibial fractures at Quetta Hospital 40 had been managed by external fixation and 24 by plaster backslab after wound excision. Again all were Gustilo grade II or III (Fig. 4). They were treated at a mean of about five days after injury; the shorter time than that for femoral fractures may reflect the relative ease of evacuating patients with below-knee injuries.

Patients with tibial fractures treated by external fixation spent a mean of 62 days in hospital, much longer than the mean 34 days for those with fractures managed in plaster. This was partly because of difficulties with the external fixator and also because four patients required bone grafting, implying that more delay in union occurred in the external fixator group.

After simple wound excision and delayed primary closure or skin grafting, external fixation seemed to confer few advantages, unless sophisticated techniques such as vascularised flaps were being considered. Simple plaster slabs
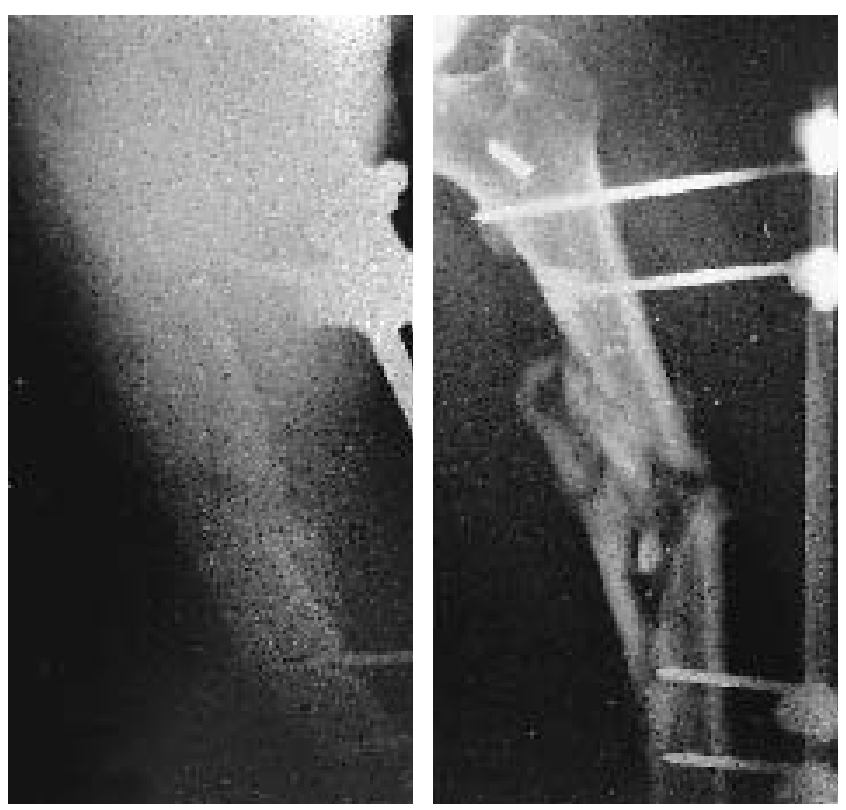

Fig. 3

A high-velocity grade- 2 fracture. Note the bullet and its fragments. Siting of the pins is extremely difficult without image intensification.

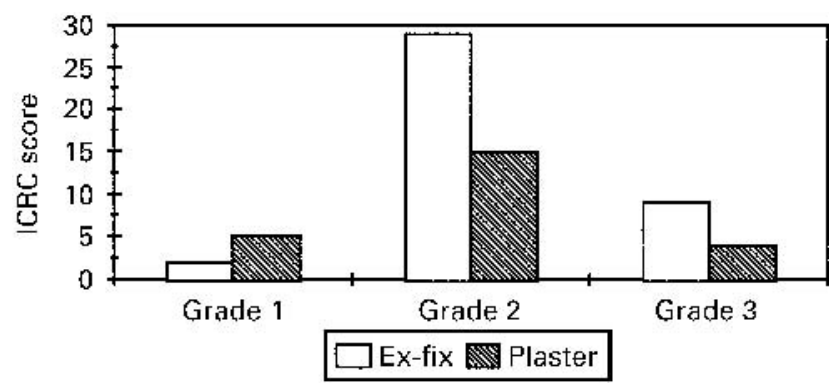

Fig. 4

The ICRC classification of tibial fractures.

allowed early discharge with marginally fewer complications (nine interventions in the externally fixed group compared with seven in the plaster group).

Humeral fractures. Those reviewed had been treated at Lopiding Hospital in Kenya and ICRC wound scores had not been used. In 51 fractures the severity of the injury was indicated by the number of fragments of bone, and the size of the soft-tissue injury was assumed indirectly. Treatment had been by simple excision, then either external fixation or by gravitational traction in a collar-and-cuff sling.

The long delay before treatment of a mean of 26 days reflects the logistical problems of the area. The severity of injuries treated by a collar-and-cuff sling was not grossly different from that of injury treated by external fixation: in both the externally fixed and the traction groups there was a mean of eight major fracture fragments. There were more operations and more complications after external fixation, largely consisting of adjustments to the fixator and the 


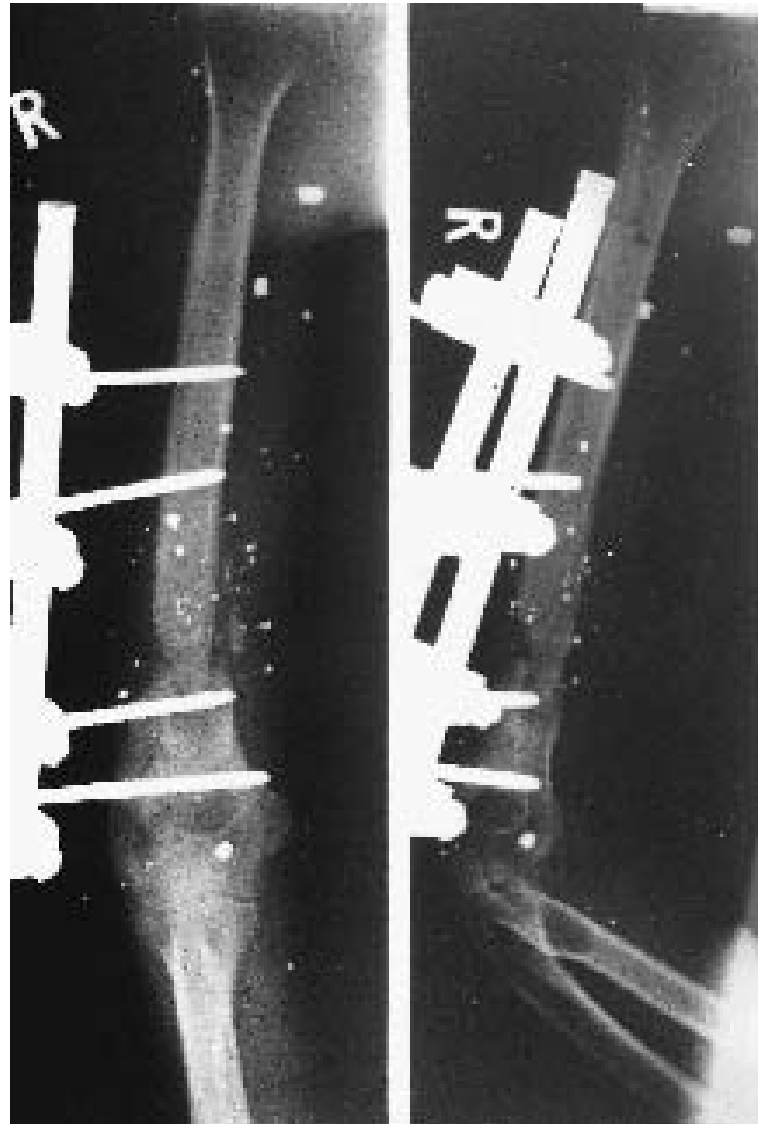

Fig. 5

A low humeral fracture which would be a challenge to manage by any technique. The external fixator is holding the fracture apart.

resiting of the pins, as represented by the number of interventions (ten in the external fixation group and only four in the traction group). Both methods of treatment produced healing in functionally acceptable positions with no difference in overall alignment.

An important finding was that external fixation had been used to try to restore equal arm length in the face of formidable soft-tissue wounds (Fig. 5). Although armlength discrepancies are relatively unimportant, efforts had been made to restore length which increased both time to union and the length of stay in hospital. This was highly significant as the externally fixed group spent a mean of 100 days in hospital and those simply treated in a splint only 42 days.

\section{DISCUSSION}

Modern fracture surgery has advanced considerably in the last two or three decades, as have anaesthesia, technology and nursing skills, but in world terms such high technology is irrelevant compared with the basic requirements of clean water, light and power. Western expertise should not attempt to transfer high technology to an infrastructure which is not yet ready to support it. The results of large numbers of open fractures of long bones treated by general surgeons show that external fixation failed to confer any significant advantage. In some situations, such as the management of humeral fractures, efforts to restore length actually caused delayed union and made management much more difficult. In general, the results were anatomically and functionally acceptable and are a tribute to the surgeons concerned.

The key to success in remote parts of the world lies in excellent primary surgery, with good wound excision and careful dressing (Coupland 1993). Plaster and the use of traction need careful attention to detail, but local staff can be trained to a remarkably high standard and often take pride in their detailed involvement. The management of external fixation is more likely to go wrong and sometimes requires specialised backup.

The experience of audit and research in an unconventional field confirms the fundamental need for all surgeons to learn and understand basic principles, and to apply them thoroughly. The high technology of surgery, like that of the Kalashnikov rifle, is only as effective or as devastating as the individual who controls it.

The author wishes to thank D. McGurty of the Audit Section of the Department of Orthopaedic and Trauma Surgery, who performed the final statistical analysis and R. Coupland and R. Gray of the Medical Division of the International Committee of the Red Cross who provided expert support and advice throughout this project.

No benefits in any form have been received or will be received from a commercial party related directly or indirectly to the subject of this article.

\section{REFERENCES}

Coupland RM. A management algorithm for chronically exposed war wounds of bone. Injury 1990;21:101-3.

Coupland RM. War wounds of limbs: surgical management. Oxford, Butterworth Heineman, 1993.

Goonetilleke G. Management of missile injuries in a combat zone in Sri Lanka. Ceylon Med J 1993;38:83-6.

Korzinek K, Smerdelj M, Tripkovic B. War injuries of the extremities: use of the CMC fixator. Lijec Vjesn 1991;113:238-42. 